\title{
Nostalgia-Driven Design and Digitalization of Brand Spokes- Characters for Generation Z
}

\author{
Huanshu Jiang ${ }^{1 \mathrm{a}}$, Jie Yao ${ }^{2 b^{*}}$, Peiyao Cheng ${ }^{3 c}$, Shumeng Hou $^{4 \mathrm{~d}}$ \\ ${ }^{1}$ School of Humanities and Social Sciences Harbin Institute of Technology (Shenzhen), Shenzhen, China \\ ${ }^{2}$ School of Humanities and Social Sciences Harbin Institute of Technology (Shenzhen), Shenzhen, China \\ ${ }^{3}$ School of Humanities and Social Sciences Harbin Institute of Technology (Shenzhen), Shenzhen, China \\ ${ }^{4}$ School of Humanities and Social Sciences Harbin Institute of Technology (Shenzhen), Shenzhen, China
}

\begin{abstract}
Generation Z, as the first generation growing up in the environment of globalization, has emerged as a new important consumer group worldwide. Compared with other generations, members of Generation $\mathrm{Z}$ possess some notable characteristics such as lower brand loyalty and less interest in mainstream products. Meanwhile, they also display a strong tendency to nostalgia, which has been a widelyused theme in marketing and proved to enhance consumers' brand attitudes and purchasing intentions. Based on the unique preferences and needs of Generation Z, this study explored the innovative strategy of nostalgia-driven design of brand spokes-characters and related digitalization, which are popular design elements in brand promotion and advertising. Through a multi-method qualitative approach (including user interviews, creative exercises, and content analysis), it provided important consumer insights into the attitudes of Generation $\mathrm{Z}$ on brand spokes-characters that can trigger nostalgia, as well as their preferences for design strategies focusing on two types of nostalgia, i.e., personal nostalgia and historical nostalgia. Given the special preference of Generation $Z$ for story-based brand spokes-characters, this study also emphasized the value of advanced digital media technology for creating truly nostalgic story scenes that could continue to impress consumers. Such findings have formed an important basis for ongoing quantitative studies that further examine the effectiveness of nostalgia-driven design for Generation $Z$.
\end{abstract}

\section{INTRODUCTION}

Nostalgia has been widely used in brand design and marketing in Western markets. In China, nostalgiarelated phenomena such as "the great mass fervor of Hanfu (traditional clothes from the Han Dynasty) " and " Guochao (incorporation of Chinese elements into fashion design)" have also emerged and become increasingly popular in recent years, particularly among members of Generation Z. As the first generation of consumers growing up in a globalized world and largely influenced by the Internet, Generation $\mathrm{Z}$ consumers have displayed unique characteristics that might require innovative brand design strategies to acquire new customers and cultivate positive brand relationships.

\subsection{Research on Generation Z}

Current definitions of "Generation Z" are not completely unified, but existing literature generally describes Generation $\mathrm{Z}$ as "a group lasting about 15 years from 1997" 12, while emphasizing that they are a generation living in a world with smartphones, laptops, accessible
Internet and digital media 34. Not surprising, Generation $\mathrm{Z}$ are more active in their thinking, and more sensitive and open to new things. They have shown a very strong power for consumption of expensive clothing of international brands and high-end products such as computers and digital cameras 5 .

On the other hand, the brand attitude of Generation Z is very different from that of other generations. Generation $\mathrm{Z}$ consumers are characterized by low brand loyalty, rejection of expensive and popular items, and love for sharing beloved brands. First, they are more cautious and pickier, which leads to high sensitivity to brands and low brand loyalty 6 . Second, they are very pragmatic and reject things that are too expensive, popular or uniform (except for brands that they consider "cool") 7. Third, Generation $\mathrm{Z}$ are voluntary brand marketers who believe it is necessary to talk about their beloved brands with people belonging to their social networks and share their experiences on social media 8 .

\subsection{Research on Nostalgia}

Among various definitions of nostalgia, most scholars have agreed that nostalgia is "a preference (general liking,

a903012516@qq.com

b*yaojiejulie@hit.edu.cn

cchengpeiyao@hit.edu.cn

dhoushumeng@hit.edu.cn 
positive attitude, or favorable affect) toward objects (people, places, or things) that were more common (popular, fashionable, or widely circulated) when one was younger (in early adulthood, in adolescence, in childhood, or even before birth) " 9. Regarding types of nostalgia, comparison between personal nostalgia and historical nostalgia has been made in prior research 101112 . Personal nostalgia is initiated by an individual's direct experience ("the way I was", sometimes referred as "real nostalgia"), whereas historical nostalgia stems from an indirectly experienced historical period or era ("the way it was", also called "simulated and collective nostalgia"). Therefore, personal nostalgia is linked with personal identity and connections to others, whereas historical nostalgia is related to sociopolitical factors 131415 .

\subsection{Research on Generation Z Characteristics and Nostalgia}

Generation $\mathrm{Z}$ are prone to nostalgia, given some key characteristics exhibited by them. Due to the accelerating pace of technological updates, members of Generation $Z$ pay more attention to security than ever before, and generally have a strong sense of crisis and worry about their future to some extent 16 . They also show a higher tendency of loneliness and depression than other generations 17. These negative emotions such as insecurity and loneliness easily felt by Generation $\mathrm{Z}$ have been found to motivate purchasing of nostalgia-triggering products 10 , which can help consumers recover good feelings towards the past and relieve their nervous moods 18.

Another characteristic of Generation $\mathrm{Z}$ related to nostalgia is value of individuality and personality 719 , which is similar to that of those who like nostalgic products/brands and often describe themselves as fashionconscious and non-conformist 20. Such consumers don't like popular and ordinary contents, prefer something that shows personality, and often re-evaluate, question and criticize everything 672122. In addition, Generation Z tend to immerse themselves in virtual worlds by means of video games and 24-hour social networks, where people's experience is similar to the ideal of imagination 6 . Similarly, consumers can mediate and express their dissatisfaction with the modern society through contact with nostalgic brands and nostalgic aesthetics, because nostalgic things are considered real, credible and expressive, and keep a distance from products that are considered modern and fake 23 .

\subsection{The Application of Nostalgia in Brand Design}

Among various marketing methods that promote brand attitudes, nostalgia has been a popular theme in product and brand design. Many companies have adopted the nostalgic style, hoping to enhance consumers' attitudes towards their brands and increase the possibility of purchasing. On the other hand, as a unique brand element and means of brand promotion, spokes-characters have been more and more widely used in brand design and advertising 24. Spokes-characters are roles used by enterprises to promote products or brands, including both non-human virtual characters such as Duracell Bunny and virtual human characters such as Ronald McDonald. Many studies have explored their characteristics and functions, one of which is the relationship between nostalgia and brand attitude 2526. How to apply nostalgic elements to the design of brand spokes-characters, so as to effectively promote consumers' positive attitude towards the brand, has important implications for brand research and practice.

\subsection{Objectives of the Study}

Prior studies have confirmed the usefulness of brand spokes-characters in general, but specific design factors such as nostalgia and its influence on specific groups of people remain unclear 27. Given the emerging large consumer group from Generation $\mathrm{Z}$ and their various characteristics related to nostalgia, the relationship between nostalgia and brand spokes-characters is worthy of further exploration. This study sought to understand the importance of nostalgia-driven design of brand spokescharacters from perspective of Generation Z, and to help enhance their trusts for brand spokes-characters and ultimately their brand attitudes. It also formed the basis for follow-up studies that sought to quantify the influences of nostalgia-driven design of brand spokescharacters.

This research has both theoretical and practical significance. Theoretically, this study aimed to provide empirical evidence from Generation $Z$ for the usefulness of nostalgic brand spokes-characters to modern brands, which will contribute to further theoretical advancements in the field. In practice, the results of this study can help brands measure and judge the feasibility of nostalgic marketing strategies on the newly emerged consumer groups, so as to improve brand attractiveness and brand loyalty, and promote sustainable consumer behaviors.

\section{Methods}

\subsection{Study Design}

A multi-method qualitative approach was undertaken, which collected detailed user data by means of semistructured one-on-one interviews that integrated openended and evaluation questions, as well as creative exercises. A detailed interview protocol was developed and questions covered a wide range of issues related to nostalgia-oriented design in products and brands, which were divided into the following four sections.

- General attitudes and preferences regarding nostalgic styles, and evaluation of design examples of products/posters/packages/clothes with nostalgic elements

- Perceptions of brands in general and specifically Chinese brands

- Perceptions of brand spokes-characters, and views about personal and historical nostalgia in relation to brand spokes-characters, using "Hot Kid" as an example 
- Creative exercises for listing out specific elements that might trigger personal nostalgia from Generation $\mathrm{Z}$

\subsection{Sample and Data Collection}

Based on the general definition of Generation Z, this study focused on college students born after 1997, and therefore invited 10 interviewees of Generation $\mathrm{Z}$ to participate who were born between 1997 and 2001. They were evenly split in terms of gender and came from various academic majors. Detailed one-on-one interviews were conducted with the software Tencent Conference, each of which lasted about 50 minutes. Interview materials were sent to the interviewees three days in advance for them to read before and during the interview. With the consent of the interviewees, audio recording of interviews were taken and used for data analysis.

\subsection{Data Analysis}

Based on standard qualitative data processing, a total of 75 initial concepts were obtained, each with a representative sentence to define the phenomenon. Next, spindle coding was performed on the 75 initial concepts, resulting in eight main themes that were further summarized into the following four core categories: (1) nostalgia tendency of Generation $\mathrm{Z}$ and their views about nostalgic design styles, (2) perceptions of brands, (3) perceptions of brand spokes-characters, particularly nostalgia-driven brand spokes-characters, (4) elements that can trigger personal nostalgia from Generation Z.

\section{Results}

\subsection{Nostalgia Tendency of Generation Z and Their Views about Nostalgic Design Styles}

"Reminiscing about childhood" and "nostalgia" were commonly found among the participants. Childhood memories were frequently recalled by them, most of whom $(\mathrm{N}=9)$ indicated that they often thought of the happy time spent in childhood with family and classmates. Memories of the past were evoked when they saw scenes and objects related to their childhoods, or when they felt stressed and tried to ease unhappy moods by reflecting upon good early childhood experiences. In addition, several participants $(\mathrm{N}=4)$ also often fantasized about ancient times or the period of the Republic of China, with a deep yearning for plots and characters in history books and the civilization of each dynasty.

Regarding nostalgic design styles, most of the participants $(\mathrm{N}=8)$ were receptive. Whether it was nostalgic product design, poster design, or packaging design, they could feel the power of time and history, which gave the nostalgic style a sense of being high-end and unique. The strong contrast between nostalgic style and modern style was also eye-catching, the former standing out with a novel visual impact and arousing their curiosity. Their interests in nostalgic styles were clearly expressed, for example, "Nostalgic-style products are very attractive by themselves", "I like the nostalgic style", and "Nostalgic elements will add points to the product."

In addition, three main factors were mentioned by the participants that affected their preferences for nostalgic design. First of all, the layout should be simple, especially in product design, since overly complex elements could lead to cognitive burden. In general, the font design should be simple and regular, with key points highlighted and fancy layouts avoided. Second, the theme must be clear, since design features adopted from the past are usually unfamiliar to Generation $Z$, and clearer texts are required. Finally, as elegant nostalgia was preferred, designers should avoid over-saturated and dull colors.

\subsection{Perceptions of Brands}

There was a clear gender difference in terms of brand preferences. Male participants paid more attention to technology brands (such as Huawei, NIO and Bilibili), whereas females were more interested in cosmetics and snack brands (such as Pechoin, Ganki Forest and White Rabbit). Their purchasing behaviors also differed. Several boys $(\mathrm{N}=3)$ expressed no special brand preferences and made purchases mainly based on cost-effectiveness and convenience, while girls paid more attention to brand reputations, and cared more about well-developed brands rather than new brands. Regarding "domestic brands versus foreign brands", most interviewees indicated that domestic brands should be given priority in most cases. Three interviewees mentioned that they tended to consider foreign brands in the categories of cosmetics, toys and electronics, but they would not exclude domestic brands.

\subsection{Perceptions of Brand Spokes-Characters}

Most interviewees could recall some common brand spokes-characters, such as Mr. Michelin and Hot Kid, although they might have never heard of the term "brand spokes-characters". A few interviewees initially believed that brand spokes-characters were indistinguishable from brand logos. On the other hand, some of the participants believed that brand spokes-characters were more attractive than ordinary celebrity endorsements. Regarding the design of brand spokes-characters, cuteness was the greatest attraction for the participants, who loved cute images and character settings such as those in Hot Kid and Qoo designs. At the same time, the use of dynamic storylines to create brand spokes-characters can enrich them and attract attention continuously.

Regarding perceptions of nostalgia-driven brand spokes-characters, Hot Kid was used as an example in the interview, with three design versions of Hot Kid presented to the participants (i.e., the classic version, a version that sought to trigger personal nostalgia, and a version for historical nostalgia). It turned out that for Generation Z, the "personal nostalgia" they felt was very different from the "historical nostalgia". The presentation of personal nostalgia was more likely to evoke their own past memories, while the historical nostalgia style was more like a dress-up game, reflecting the past era through 
changes in clothing and bringing a relatively weaker impact. Not surprising, the version of Hot Kid that triggered personal nostalgia received the highest number of votes.

Participants' resonance with personal-nostalgia-driven design might be attributed to several factors. Nostalgia can link the brand spokes-characters with the user's own emotions, who are more likely to be touched and accept the brand spokes-characters. Another reason is that " reminiscing about the past" is very common among members of Generation Z, who have expressed their desires to recall past experiences, especially childhood memories which can bring warmth and healing to their present life. On the other hand, historical nostalgia also has some influences, as most interviewees expressed that it was acceptable to use brand spokes-characters to trigger historical nostalgia in modern brands. They welcomed to see images of brand spokes-characters with a focus on historical nostalgia, especially during some traditional Chinese festivals.

\subsection{Elements Triggering Personal Nostalgia}

In the creative exercise of filling in the personal nostalgia card with key elements, a total of 134 valid entries were collected, among which the most frequently mentioned items were "bicycle" and " spicy Chinese snacks", as well as "family" being a person-related word. The most frequently mentioned categories were campus life, childhood, toys/games, and cartoons, echoing the aforementioned results of "brand spokes-characters that evoke personal nostalgia". Among the scenes and costumes that evoked personal nostalgia, school-related scenes and costumes impressed the participants most.

\subsection{Digital Media Technology for Creating Nostalgia-Driven Story Scenes}

For the design of brand spokes-characters, the importance of developing related stories for them was also mentioned during the interview, particularly the use of truly restored original story scenes that could trigger the personal nostalgia of Generation Z. For example, "Haier Brothers", the original spokes-character for the brand Haier that was broadcasted in 1995 and became memories of many people, was shown to the interviewees. Several participants shared their past experiences with this spokes-character, such as: "I saw this cartoon when I was a child", "I liked this cartoon very much when I was a child", "I still remember its theme song". Overall, the image of Haier Brothers presented to them evoked their good childhood memories.

On the other hand, the re-introduction of the "Haier Brothers" storyline by Haier in 2018 was not as good as expected. "Haier Brothers Cosmic Adventure", as the new version of "Haier Brothers", did not impress members of Generation $\mathrm{Z}$ who thought the animation technology used did not show much progress and the storyline was very outdated. Clearly, personal nostalgia towards the spokescharacter alone was short-lived without continuing support of related nostalgic storytelling, which requires advanced digital media technology for designing scenes and animation effects. Designers should make full use of digital techniques to enhance user immersion in nostalgiadriven scenes and evoke nostalgic feelings in a sustainable way, in order to improve the trust of Generation $\mathrm{Z}$ in brand spokes-characters.

\section{Discussion AND ConCLUSION}

In summary, Generation $\mathrm{Z}$ have general preferences for nostalgia-driven design styles, which is consistent with prior research on key characteristics of Generation $\mathrm{Z}$ that overlap with nostalgia enthusiasts. However, not all nostalgic styles are loved by Generation Z, who favor simple design features such as regulated typography, prominent text titles, square fonts and restorative nostalgic illustrations. Regarding brand attitudes, Generation $\mathrm{Z}$ are overall picky and rational, who can clearly state the advantages and disadvantages of the brand under evaluation. Meanwhile, most of them hold high expectations for and are willing to support Chinese brands.

In comparison with brand spokes-characters without nostalgic elements, Generation $\mathrm{Z}$ is more inclined to nostalgia-driven brand spokes-characters, especially those that trigger personal nostalgia. Generation $\mathrm{Z}$ value the feeling of personal nostalgia, which can enhance their love and trust in the brand spokes-characters. Main sources of personal nostalgia are from their campus life, family life, childhood games/toys, childhood snacks, as well as cartoon/animated characters, among which campus life is the most important source. Compared with personal nostalgia, historical nostalgia might have a weaker effect, but can still play an important role particularly during traditional Chinese festivals. In either type of nostalgia-driven design strategy, innovative digital media techniques are needed to create believable, nostalgic stories and scenes that can continue to impress Generation $\mathrm{Z}$ and enhance their attitudes towards the brand spokes-characters and brands represented.

\subsection{Limitations and Future Research}

This exploratory study has several limitations. First of all, it employed qualitative methods with a limited sample size, so the results might not be generalizable. Based on this study, however, a quantitative experiment as well as survey research are currently being conducted to expand the study and further quantify the influences of brand spokes-characters that trigger nostalgia for Generation Z. Second, this study used Hot Kid as the main example for evaluation of nostalgia-driven brand spokes-characters, which only represents the brand of Want Want that mainly focuses on children's food. Since Hot Kid has existed in the childhood memories of most members of Generation $\mathrm{Z}$, not surprising that it is more likely to trigger personal nostalgia from them. At the same time, most interviewees initially had a high positive brand attitude towards Want Want, so it might be challenging to separate the effect of nostalgia on the brand attitude from their initial attitudes. Further research is being conducted that use different types of brand spokes-characters for 
consumers to evaluate, in order to accurately determine the unique impacts of nostalgia-driven design of brand spokes-characters. Given the limited number of successful brand spokes-characters in China, brand researchers and designers can benefit from the findings of this study and follow-up research, and leverage the power of nostalgia to further build up brand spokes-characters and brands that Generation $\mathrm{Z}$ love.

\section{REFERENCES}

1. Williams, A. (2015). Move over, millennials, here comes Generation Z. The New York Times, 18.

2. Dimock, M. (2019). Defining generations: Where Millennials end and Generation $\mathrm{Z}$ begins. Pew Research Center, 17, 1-7.

3. Singh, A. P., \& Dangmei, J. (2016). Understanding the generation $\mathrm{Z}$ : the future workforce. South-Asian Journal of Multidisciplinary Studies, 3(3), 1-5.

4. Tulgan, B. (2013). Meet Generation Z: The second generation within the giant" Millennial" cohort. Rainmaker Thinking, 125.

5. Chen, W. (2017). How to implant brand into the mind of post-95 consumers. Voice \& Screen World(05),69.

6. Wood, S. (2013). Generation Z as consumers: trends and innovation. Institute for Emerging Issues: $\mathrm{NC}$ State University, 1-3.

7. Töröcsik, M., Szücs, K., \& Kehl, D. (2014). How generations think: research on generation z. Acta universitatis Sapientiae, communicatio, 1(1), 23-45.

8. Riivits-Arkonsuo, I., \& Leppiman, A. (2015). Young consumers and their brand love. International Journal of Business and Social Research, 5(10), 3-44.

9. Holbrook, M. B., \& Schindler, R. M. (2003). Nostalgic bonding: Exploring the role of nostalgia in the consumption experience. Journal of Consumer Behaviour: An International Research Review, 3(2), 107-127.

10. Ju, I., Jun, J. W., Dodoo, N. A., \& Morris, J. (2017). The influence of life satisfaction on nostalgic advertising and attitude toward a brand. Journal of Marketing Communications, 23(4), 413-427.

11. Pascal, V. J., Sprott, D. E., \& Muehling, D. D. (2002). The influence of evoked nostalgia on consumers' responses to advertising: An exploratory study. Journal of Current Issues \& Research in Advertising, 24(1), 39-47.

12. Muehling, D. D., \& Pascal, V. J. (2011). An empirical investigation of the differential effects of personal, historical, and non-nostalgic advertising on consumer responses. Journal of Advertising, 40(2), 107-122.

13. Merchant, A., Latour, K., Ford, J. B., \& Latour, M. S. (2013). How Strong is the Pull of the Past?: Measuring Personal Nostalgia Evoked by Advertising. Journal of Advertising Research, 53(2), 150-165.
14. Baker, S. M., \& Kennedy, P. F. (1994). Death by nostalgia: A diagnosis of context-specific cases. ACR North American Advances.

15. Batcho, K. I. (2007). Nostalgia and the emotional tone and content of song lyrics. The American Journal of Psychology, 361-381.

16. Lian, S., Feng, D., \&Lu, Y. (2016). Analysis of the characteristics, leverage and work thinking of the new social class in China at present-a survey report on the new social class. China Youth Study(11),5663.

17. A.W. GEIGER., \&LESLIE DAVIS, A growing number of American teenagers - particularly girls are facing depression, https://www.pewresearch.org/facttank/2019/07/12/a-growing-number-of-americanteenagers-particularly-girls-are-facing-depression/

18. Zhou, L., Wang, T., Zhang, Q., \& Mou, Y. (2013). Consumer insecurity and preference for nostalgic products: Evidence from China. Journal of Business Research, 66(12), 2406-2411.

19. Schwieger, D., \& Ladwig, C. (2018). Reaching and retaining the next generation: Adapting to the expectations of Gen $\mathrm{Z}$ in the classroom. Information Systems Education Journal, 16(3), 45.

20. Hemetsberger, A., Kittinger-Rosanelli, C., \& Mueller, B. (2011). "Grandma'S Fridge Is Cool"-the Meaning of Retro Brands For Young Consumers. in NA - Advances in Consumer Research Volume 38, eds.

21. Li, L., \& Zhang, Y. (2019). Grasp the focus analysis of the post-95 audience. Journal of Education and Media Studies(05),25-28.

22. Yan, D. (2017). On the Deconstructionism Influence of New Media on the Youth Culture of Post-95s Generation. Contemporary Youth Research(06),3540.

23. Olsson, M., \& Höglund, J. (2019). How young consumers use retro brands and retro products to mediate and express discontent towards the present. University of Gothenburg.

24. Zhang, Y. (2015). The Impact of Spokescharacters's Likability and Nostalgic on Brand Loyalty (Unpublished master's thesis). Nanjing Normal University.

25. Callcott, M. F., \& Alvey, P. A. (1991). Toons sell... and sometimes they don't: An advertising spokescharacter typology and exploratory study. In Proceedings of the 1991 Conference of the American Academy of Advertising (pp. 43-52). New York: D'Arcy Masius Benton and Bowles.

26. Zhang, N. (2013). The Influence of Spokescharacters on Brand Equity: The Mediation of Brand Experience and the Moderation of Characteristics of the Consumers and Products (Unpublished doctorial dissertation). Wuhan University.

27. Phillips, B. J., Sedgewick, J. R., \& Slobodzian, A. D. (2019). Spokes-Characters in Print Advertising: An 
Update and Extension. Journal of Current Issues \&
Research in Advertising, 40(2), 214-228. 